\title{
Symptomatic first urinary tract infection in children and underlying kidney and urinary ttract abnormalities from a tertiary care hospital in India
}

\section{Dey $\mathrm{P} \mathrm{K}^{1}$ Banerjee $\mathrm{J}^{2}$ Singh R $\mathrm{P}^{3}$ Pan $\mathrm{A}^{4}$ Chatterjee $\mathrm{A}^{5}$}

${ }^{1}$ RMO cum Clinical Tutor. Department of Pediatrics, Medical College,Kolkata, ${ }^{2}$ Assistant Professor, Department of Physiology, R.G.Kar Medical college, Kolkata, ${ }^{3}$ Professor and Head, Department of Paediatrics, GSVM Medical College, Kanpur, ${ }^{4}$ Lecturer,Department of Pediatrics,College of Medical Sciences,Bharatpur, ${ }^{5}$ Assistant Professor,Department of Pediatrics,Calcutta National Medical College

\section{ABSTRACT \\ Objective}

The aim of this study was to describe the characteristics and the clinical evolution of first documented symptomatic Urinary Tract Infection and to detect underlying abnormalities of the kidney and urinary tract if any.

\section{Methods}

Prospective observational study on 102 patients ( 6 months to $5 \mathrm{yrs}$ ) with first documented symptomatic Urinary Tract Infection diagnosed by positive urine culture in the department of Paediatrics, G.S.V.M Medical College, Kanpur, India between January 2008 and June 2009. Antibiotics were given according to the sensitivity pattern. All children were evaluated with renal bladder ultrasonogram and voiding cystourethrography.

\section{Results}

Out of 102 patients 62 (60.78\%) girls and 40 (39.21\%) boys, most of the patients (62.7\%) within 6 months to 2 years old. The commonest presentation was fever (84.3\%).The commonest organism was E.Coli (80.37\%). Overall most common underlying abnormality was VUR, found in $31(30.31 \%)$ children. Other abnormalities were urolithiasis(4.9\%), ureteropelvic junction obstruction (3.92\%), Mild hydronephrosis (2.9\%), ureteric duplex(0.98\%), posterior urethral valve(0.98\%), renal duplex (0.98\%).

\section{Conclusion}

In our study $45.09 \%$ children had underlying abnormalities which may be a potential risk factor for urinary tract infection. Better recognition of risk factors, prompt diagnosis and early intervention are sufficient enough to maintain normal renal function and healthy lifestyle. 
Journal of College of Medical Sciences-Nepal, 2013, Vol-9, No-3,

\section{INTRODUCTION}

Urinary tract infection(UTI) is one of the most common bacterial infections in children,with $8 \%$ of girls and $2 \%$ of boys experiencing at least one UTI by the age of 7 years. ${ }^{1}$ The risk of UTI also varies between different age groups. In uncircumcised infant males the incidence of UTI is $0.7 \%$, higher than the $0.1-0.4 \%$ reported incidence in infant females. ${ }^{2}$ The risk of UTI increases after infancy in females to $0.9-1.4 \%$ before age 5 , and to $0.7-2.3 \%$ in school age girls. In contrast, the risk of UTI drops in males after infancy to $0.1-0.2 \%$ under age 5 and $0.04-0.2 \%$ in school age boys. ${ }^{2}$

UTI in young children serve as a marker for abnormalities of the urinary tract. ${ }^{3}$ Renal bladder ultrasonography (RBUS) and voiding cystourethrography (VCUG) examinations have been standard diagnostic tools for children with first UTI to identify possible structural or functional abnormalities of the urinary tract, such as vesicoureteral reflux (VUR). This diagnosis often leads to a radiographic workup to look for correctable urinary tract abnormalities that may predispose the child to infection and these abnormalities were thought to be important to detect as they have been suspected to predispose the child to repeated episodes of pyelonephritis and potentially irreversible renal damage. ${ }^{4,5}$ On this background the goal was to diagnose first UTI, and to identify underlying kidney and urinary tract abnormalities in children of 6months to 5 years age groups in India.

The aim of this prospective study was to describe the characteristics and the clinical evolution of first documented symptomatic UTI that was diagnosed by systematic screening in the peadiatric department of children in whom UTI was considered a possibility on clinical grounds and to detect underlying abnormalities of the kidney and urinary tract if any.

\section{METHODS}

An observational prospective study was conducted in the department of Paediatrics, G.S.V.M Medical College, Kanpur, India between January 2008 and June 2009. In this study 102 children were included according to inclusion and exclusion criteria. Inclusion criteria were; age between 6months to 5 years, documented symptomatic culture proven first UTI cases and exclusion criteria were; previous history of UTI, h/o antibiotic intake within 7 days, any obvious neurological abnormities and impairment. We prospectively collected data on 150 children who were diagnosed with a clinically proven first episode of UTI at the pediatric department of our hospital. First of all different steps of the study were fully described to patient's parents and their consent were obtained. Then all children were undergone history taking, clinical examination and proper investigations. Detailed history of fever, vomiting, oedema, loose motions and urinary complaints like frequency, dysuria, pain abdomen, hematuria etc were taken. All patients were examined clinically and BP was recorded. First UTI was defined as first documented symptomatic culture proven UTI. All urine samples from children younger than 24 months were obtained by suprapubic aspiration or a single bladder catheterization and from older children by clean catch or bladder single catheterization. UTI was diagnosed by; the presence of any growth on suprapubic specimen or $>=50 \times 10^{3} \mathrm{CFU} / \mathrm{ml}$ of catheterized sample, or more than $10^{5} \mathrm{CFU} / \mathrm{ml}$ organisms of a single species. ${ }^{6}$ Culture sensitivity of urine sample and characterization of the pathogens was performed according to standardized procedures in the laboratory of the Department of Microbiology of our institution. Among all 150 symptomatic children 102 children were included in our study. Forty eight patients with incomplete investigations (Culture 
Dey PK et al. symptomatic first urinary tract.

negativity and imaging work up) were excluded from the study.

These children were treated by antibiotics for 7 to 10 days. The antibiotics were changed, if necessary, according to the results of bacterial sensitivity. Patients with abnormal imaging received antibiotics for 14 days. Prophylaxis was given thereafter until results of the VCUG were available.

All 102 children were evaluated with an ultra sonogram (RBUS) and Voiding cystourethrography (VCUG). The US examinations were performed by the same trained radiologists using adapted equipment, with high resolution curvilinear and linear transducers. It consisted of examination of the kidneys in order to show the kidney size, renal outlet obstruction (such as pelvicuretro junction stenosis), collecting system dilatation, parenchymal structure. Also examination of the bladder was done in order to identify dilatation of the distal ureters, hypertrophy of the bladder wall, and presence of ureteroceles. VCUG was generally performed at least 1 month after the first UTI under fluoroscopic guidance with the child awake as described previously. ${ }^{\text {? }}$ VUR was graded by means of the International Reflux Study Committee classification. ${ }^{8}$

The study protocol was reviewed and approved by the Ethics committee of our institution. Categorical data are shown as proportions and expressed as percentage. All statistical analysis was done using SPSS version17.

\section{RESULT}

In our study among the 102 children $62(60.78 \%)$ were girls and 40 (39.21\%) were boys. Demographics and initial clinical data are summarized in Table-1. In all 102 children $62.7 \%$ had their first UTI before the age of 2 years among them $23.5 \%$ were between 6 months to 1 year of age and $39.2 \%$ were between $>1$ year to 2 years of age, whereas $37.3 \%$ children were between $>2$ years to 5 years of age (Table 1 ). The most common pathogen was Escherichia coli, which grew in $83(80.37 \%)$ cultures (Fig-1). Frequencies of other pathogens (Fig-1) were as follows: Klebsiella pneumoniae, 10(9.8\%); Proteus mirabilis, 5 (5.8\%); Pseudomonas aeruginosa, 3 (2.94\%) and Staphylococcus epidermidis, 1 (1.09\%).

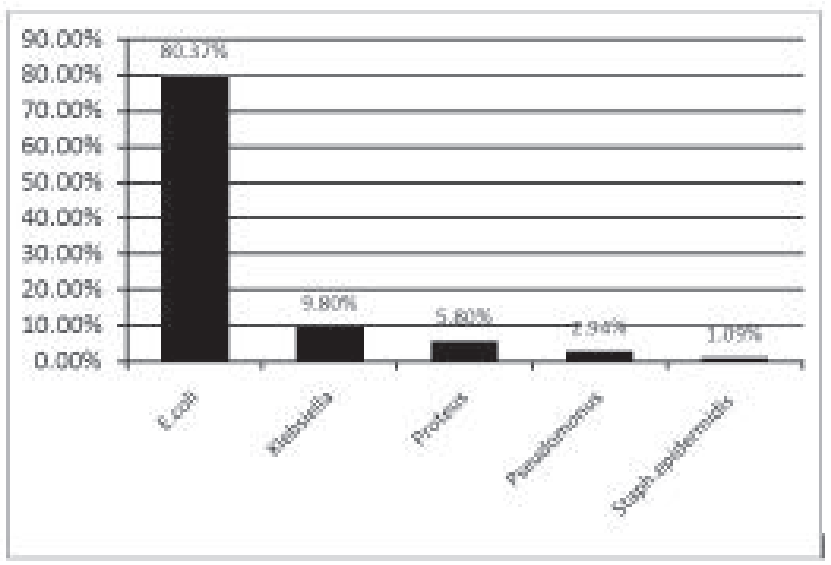

Figure 1: Percentage of different organism in symptomatic first UTI

Among the common general clinical symptoms, most common symptom was fever (84.31\%). Fever without chill and rigor was present in $58.82 \%$ of cases and fever with chill and rigor was present in $25.49 \%$ of cases. Loose motion was present in $7.8 \%$ of cases; increased frequency of urine in $38.22 \%$ of cases. Other clinical symptoms are presented in Table -1. 
Journal of College of Medical Sciences-Nepal, 2013, Vol-9, No-3,

Table- 1

Demographics and Initial Clinical Data

DATA

Gender

Male

Female40

Age distribution

6 months - 1 year>

1 - 2 years>

$2-5$ years

Clinical manifestation

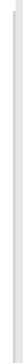

Urinary symptoms

Fever with chill and rigor

Fever without chill and rigor

Vomiting

Edema

Raised BP

Loose motions

Increased frequency of urine

Dysuria

Pain abdomen

Foul smelling urine

Hematuria

Oliguria

TOTAL NO (\%)

$(39.21 \%)$

$2(60.78 \%)$

$24(23.5 \%)$

$40(39.2 \%)$

$38(37.3 \%$

26(25.49\%)

$60(58.82 \%)$

$\mathbf{8}(7.8 \%)$

$\mathbf{9}(7.8 \%)$

$5(4.5 \%)$

8(7.8\%)

$39(38.22 \%)$

26(25.48\%)

$17(16.66 \%)$

$12(11.76 \%)$

$\mathbf{8}(5.88 \%)$

$5(4.9 \%)$

Bed wetting

12(11.76\%)

Duration of fever at entry(day) $\quad<1$

$20 \%$

1-2

$44 \%$

2-3

$18 \%$

$>3$

$18 \%$

$<4000$ cells $/ \mathrm{m}^{3}$

$5(4.9 \%)$

4000-10000 cells $/ \mathrm{m}^{3}>$

$50(49.02 \%)$

10000 cells $/ \mathrm{m}^{3}$

A renal bladder (RBUS) were obtained within 48 hours of the diagnosis of UTI in all 102 children. Of them, 73 (71.57\%) did not show any structural abnormality, whereas 29(28.43\%) patients had various structural abnormalities. RBUS suggesting VUR were found in 14 (13.73\%) patients and it is more common in female patients than the male child. Other abnormalities on US are shown in Table 2. Mild hydronephrosis was found in $3(2.9 \%)$, patients, urolithiasis in 5(4.9\%)patients, ureteropelvic junction obstruction in $4(3.92 \%)$ patients and other causes were ureteric duplex, posterior urethral valve, renal dysplasia one (0.98\%) case in each (Table-2). 
Table 2:

Abnormal USG findings in symptomatic children of first urinary tract infection according to age and sex

\begin{tabular}{|c|c|c|c|c|c|c|c|c|c|c|c|c|c|c|}
\hline \multirow{3}{*}{$\begin{array}{l}\text { Sex } \\
\text { Age } \\
\text { dysplasia }\end{array}$} & \multirow{3}{*}{$\begin{array}{c}\text { VUR } \\
\text { M }\end{array}$} & \multicolumn{3}{|c|}{ Mild } & \multicolumn{5}{|c|}{ UPJO } & \multicolumn{3}{|c|}{ Ureteric PUV } & \multicolumn{2}{|c|}{ Renal } \\
\hline & & \multicolumn{4}{|c|}{ hydronephrosis } & \multicolumn{4}{|c|}{ Urolithiasis } & \multicolumn{3}{|c|}{ duplex } & \multirow[b]{2}{*}{ M } & \multirow[b]{2}{*}{$\mathrm{F}$} \\
\hline & & $\mathrm{F}$ & M & $\mathrm{F}$ & M & $\mathrm{F}$ & $\mathrm{M}$ & $\mathrm{F}$ & M & $\mathrm{F}$ & M & $\mathrm{F}$ & & \\
\hline $6 \mathrm{mo}-1 \mathrm{yr}$ & 1 & 1 & - & 1 & 2 & 1 & - & & - & - & 1 & - & - & - \\
\hline$>1-2 \mathrm{yrs}$ & 3 & 4 & - & 1 & 1 & - & - & 1 & 1 & - & - & - & 1 & - \\
\hline$>2-5 y r s$ & 2 & 3 & 1 & & - & - & 2 & 2 & - & - & - & - & & \\
\hline Total (N) & 6 & 8 & 1 & 2 & 3 & 1 & & 3 & 1 & $\mathbf{0}$ & 1 & $\mathbf{0}$ & 1 & $\mathbf{0}$ \\
\hline & & & & & 4 & & & 5 & 1 & & 1 & & 1 & \\
\hline
\end{tabular}

VCUG was performed in all children, at least 1 month after diagnosis. Thirty one children (30.39\%) had evidence of VUR (13 boys and 18 girls). In 35 (79.55\%) renal units among cases of VUR, the reflux was classified as grade I, II, or III (low-grade) (Table 3). Only 9 renal units of 44 renal units with VUR had grade IV, V ( high grade). Only 14 of 31 patients with VUR on VCUG had an abnormal RBUS examination. However, 7 of 9 renal unit (77.78\%) with grade IV-V VUR had abnormal RBUS suggesting renal pathology. 
Journal of College of Medical Sciences-Nepal, 2013, Vol-9, No-3,

Table 3:

VCUG findings in symptomatic children of first urinary tract infection according to sex.

\begin{tabular}{|c|c|c|c|c|c|c|}
\hline & $\begin{array}{c}\text { Grade of } \\
\text { VUR }\end{array}$ & $\begin{array}{c}\text { Male } \\
\text { No }(\%)\end{array}$ & $\begin{array}{l}\text { Female } \\
\text { No }(\%)\end{array}$ & $\begin{array}{c}\text { Both }(\mathrm{n}=102) \\
\text { No }(\%)\end{array}$ & $\begin{array}{c}\text { Unilateral } \\
\text { (N ) }\end{array}$ & $\begin{array}{c}\text { Bilateral } \\
\text { (N) }\end{array}$ \\
\hline No VUR & $\mathbf{0}$ & $27(26.47 \%)$ & $44(43.13 \%)$ & $71(69.60 \%)$ & & \\
\hline \multirow[t]{8}{*}{ VUR } & I & $\begin{array}{l}4(1.94 \%) \\
\text { renal unit }\end{array}$ & $\begin{array}{l}6(2.94 \%) \\
\text { renal unit }\end{array}$ & $\begin{array}{l}10(4.88 \%) \\
\text { renal unit }\end{array}$ & 2 & 4 \\
\hline & II & $\begin{array}{l}7(3.43 \%) \\
\text { renal unit }\end{array}$ & $\begin{array}{l}9(4.42 \%) \\
\text { renal unit }\end{array}$ & $\begin{array}{l}\text { 16(7.85\%) } \\
\text { renal unit }\end{array}$ & 8 & 4 \\
\hline & III & $\begin{array}{l}3(1.47 \%) \\
\text { renal unit }\end{array}$ & $\begin{array}{l}6(2.94 \%) \\
\text { renal unit }\end{array}$ & $\begin{array}{l}9(4.41 \%) \\
\text { renal unit }\end{array}$ & 5 & 2 \\
\hline & IV & $\begin{array}{l}2(0.98 \%) \\
\text { renal unit }\end{array}$ & $\begin{array}{l}4(1.96 \%) \\
\text { renal unit }\end{array}$ & $\begin{array}{l}6(2.94 \%) \\
\text { renal unit }\end{array}$ & 2 & 2 \\
\hline & $\mathbf{V}$ & $\begin{array}{l}1(0.49 \%) \\
\text { renal unit }\end{array}$ & $\begin{array}{l}2(0.98 \%) \\
\text { renal unit }\end{array}$ & $\begin{array}{l}3(1.47 \%) \\
\text { renal unit }\end{array}$ & 1 & 1 \\
\hline & Unilateral & $9(8.82 \%)$ & $9(8.82 \%)$ & $18(17.65 \%)$ & 18 & - \\
\hline & Bilateral & $4(3.92 \%)$ & $9(8.82 \%)$ & $13(12.74 \%)$ & - & 13 \\
\hline & Total & $13(12.74 \%)$ & $18(17.64 \%)$ & $31(30.39 \%)$ & & \\
\hline
\end{tabular}




\section{DISCUSSION}

We analyzed the data of a group of children with symptomatic first UTI, in whom imaging studies were systematically performed. The diagnostic imaging methods that are usually performed to determine the UTI predisposing factors include: Renal Ultrasound ( RUS) and VCUG..

A study were conducted ${ }^{9}$ in a tertiary level hospital showed the commonest age of first symptomatic UTI is less than one year (32\%) with female preponderance (Male to Female ratio is 1:1.3) ${ }^{9}$. Our study showed that $62.7 \%$ had their first UTI before the age of 2 years among them $23.5 \%$ were between 6 months to 1year of age and $39.2 \%$ were between $>1$ year to 2 years with female preponderance $(60.78 \%$ were girls and $39.21 \%$ were boys). Another study revealed that most of infections in neonates occurred among males, but after six months of age, most of infections were seen in females. ${ }^{10}$ Female gender has increase predisposition to UTI as they have short urethra which is in close proximity with anus and wiping from back to front. ${ }^{11}$

Clinical presentation depends on age, site of infection and severity. A study ${ }^{9}$ showed fever $(82 \%)$ as the commonest presentation. In our study most common symptom was fever (84.31\%). Clinical pyelonephritis is characterized by any or all of the following: abdominal or flank pain, chills \& rigors, fever, malaise, vomiting, and occasionally diarrhea. ${ }^{11}$ In our study children also had presented with fever with chills \& rigors (25.49\%), fever without chill and rigor (58.82\%), abdominal or flank pain (16.66\%), vomiting (7.8\%), and loose motion (7.8\%). Symptoms of Cystitis include dysuria, urgency, frequent voiding, suprapubic pain ,incontinence and malodorous urine. ${ }^{11}$ Our study showed that children with first UTI had presented with increased frequency of urine $(38.22 \%)$, dysuria ( $25.48 \%)$, foul smelling urine $(11.76 \%)$, hematuria (5.88\%), oliguria $(4.9 \%)$.
Most UTIs in children are caused by Gram-negative aerobic bacilli. E. coli is the most common organism isolated; accounting for up to $80 \%$ of infections ${ }^{12}$ Our study also shows that $E$. coli remains the predominant organism causing UTIs and was isolated in $80.37 \%$ of cases. This is in accordance with the pattern of bacterial strains isolated from patients with community-acquired UTIs reported in other regions of the world in recent years. ${ }^{13,14}$

Ultrasonography (USG) was performed in all patients. In our study $71.57 \%$ did not show any structural abnormality, whereas 29(28.43\%) patients had various structural abnormalities on USG.

Renal pelvis dilatation on USG was defined as suggestive of VUR and graded as mild, moderate, or severe (hydronephrosis). ${ }^{15}$ In our study RUS suggesting VUR were found in 14 (13.73\%) patients and it is more common in female child than the male child. Other abnormalities on USG were urolithiasis $(4.9 \%)$, ureteropelvic junction obstruction $(3.92 \%)$, Mild hydronephrosis $(2.9 \%)$, ureteric duplex $(0.98 \%)$, posterior urethral valve $(0.98 \%)$, renal dysplasia $(0.98 \%)$. In our study on VCUG thirty one children (30.39\%) and 44 renal units of total 204 renal units had evidence of VUR (13 boys and 18 girls). This was similar to findings reported by Pinto et al ${ }^{16}$ which was $30 \%$ on retrospective chart review of first VCUG for UTI in 341 hispanic children between 1 month to 14 year of age. Howard et $\mathrm{al}^{17}$ which reported the presence of VUR in $39 \%$ of symptomatic Chinese children with UTI in this study, male patients had a higher frequency of reflux than females (32.5\% vs. $29 \%$ ). Hoberman study ${ }^{18}$ on 309 children with UTI, revealed VUR in 39\%. In our study among total 44 renal units of VUR, 35 renal units (79.55\% of total 44 renal units) were classified as grade I, II, or III (low- 
Journal of College of Medical Sciences-Nepal, 2013, Vol-9, No-3,

grade) and 9 renal units had grade IV, $\mathrm{V}$ ( high grade).

Only 14 of 31 patients of VUR on VCUG had an abnormal renal US examination.VUR of grade IV-V was more likely to occur among children with important abnormal ultrasonographic findings such as renal dysplasia and calyceal dilatations. Our study shows that 7 of 9 renal unit (77.78\%) with grade IV-V VUR had abnormal renal USG suggesting renal pathology. RUS was suggestive of VUR if dilatation of the pelvicalyces, dilatation of the ureters, or dilatation of the collecting system of one or both kidneys were reported. In children with normal USG, a certain number of low-grade VUR are missed. However, from previous study it is evident that the recurrence rate seen among patients with low-grade VUR is similar to that observed among patients without VUR. ${ }^{19}$ It is therefore reasonable to consider that the risk of missing lowgrade reflux would be outweighed by the benefit of avoiding unnecessary invasive examinations in the majority of these patients. All children with high-grade VUR had hydronephrosis and/or signs of dysplasia visualized on USG and would have been scheduled for more complete investigation. We believe, in common with other authors, ${ }^{20,} 21$ that USG should remain the first-line imaging work up in children with a first UTI. The presence or absence of abnormal USG represents the key for deciding about VCUG studies.

\section{CONCLUSIONS}

Urinary tract is a common site of bacterial infection in infancy and childhood with potentially important implications. This study revealed that most common underlying abnormality was VUR found in $30.39 \%$ of cases of symptomatic first UTI. Other associated urinary tract abnormalities were also seen in $14.7 \%$ of patients. Better recognition of risk factors, prompt diagnosis and early intervention are sufficient enough to maintain normal renal function and healthy lifestyle. The appropriate work-up after a UTI in a young child or infant should include a RUS, but VCUG should not be performed routinely after the first symptomatic UTI; VCUG is indicated if RBUS reveals hydronephrosis or other findings that would suggest either high-grade VUR or obstructive uropathy. Further research may deûne whether routine performance of these tests improves outcomes or whether more selective use of other tests such as DMSA may be a more effective approach in India.

\section{REFERENCES}

1. Hellstrom A, Hanson E, Hansson S, et al. Association between urinary symptoms at 7 years old and previous urinary tract infections. Arch Dis Child. 1991;66:232-234.

2. Foxman, B., Epidemiology of urinary tract infections: incidence, morbidity, and economic costs. Dis Mon, 2003. 49(2): 53-70. PMID: 12601337.

3. Lambert H, Coulthard M. The child with Urinary tract infection. Webb $\mathrm{N}$ \& Postlethwaite $\mathrm{R}$ editors in Clinical Paediatric Nephrology. 3rd edition.Oxford University press: USA; 2003; 197-226.

4. Ginsburg CM, McCracken GH Jr. Urinary tract infections in young infants. Pediatrics. 1982;69:409-412.

5. Hansson S, Bollgren I, Esbjo“ rner E, et al. Urinary tract infections in children below two years of age: a quality assurance project in 
Dey PK et al. symptomatic first urinary tract.

Sweden. The Swedish Pediatric Nephrology Association. Acta Paediatr. 1999;88:270-274.

6. Bagga A, Babu K, Kanitkar M, Srivastava RN;. Consensus statement on management of urinary tract infections. Indian Pediatr. 2001 Oct; 38(10):1106-15.

7. Mahant S, Friedman J, MacArthur C. Renal ultrasound findings and vesicoureteral reflux in children hospitalized with urinary tract infection. Arch Dis Child 2002; 86:419-21.

8. International Reflux Committee. Medical versus surgical treatment of primary vesicoureteral reflux. Pediatrics. 1981;67:392-400.

9. Islam MN, Khaleque MA ,Siddika M. Urinary Tract Infection in Children in a Tertiary Level Hospital in Bangladesh . Mymensingh Med J, 2010 ; 19(4): 482-86.

10. Chen JJ, Mao W, Homayoon K, et al. A multivariative analysis of dysfunctional elimination syndrome and its relationships with gender, urinary tract infection and vesicoureteral reflux in children. J Urol. 2004;171(5):1907-10.

11. Srivastava RN, Pankaj H. Urinary tract infection. RN Srivastava, Arvind Bagga editors in Pediatric Nephrology .5th edn. Jaypee Brothers Medical Publishers Ltd : New Delhi; 2011.Page-273-300.

12. Honkinen O, Lehtonen OP, Ruuskanen O, et al. Cohort study of bacterial species causing urinary tract infection and urinary tract abnormalities in children. BMJ. 1999;318:770 $-771$

13. Akram M, Shahid M, Khan AU. Etiology and antibiotic resistance patterns of communityacquired urinary tract infections in JN Medical hospital Aligarh, India. Ann Clin Microbiol Antimicrob. 2007;6:4.
14. Farrell DJ, Morrissey I, De Rubeis D, et al. A UK multicentre study of the antimicrobial susceptibility of bacterial pathogens causing urinary tract infection. J Infect. 2003;46:94 100.

15. Mittelstaedt CA, Vincent LM. Abdominal ultrasound. New York, NY: Churchill Livingstone, 1987:252.

16. Pinto K. Vesicoureteral reflux in the Hispanic child with urinary tract infection. J Urol. 2004;171(3):1266-1267

17. Howard RG, Roebuck DJ, Yeung PA, Chan KW, Metreweli C. Vesicoureteric reflux and renal scarring in Chinese children. Br J Radio 2001;174:331-4.

18. Hoberman A, Charron M, Hickey Rw, et al.Imaging studies after a first febrile urinary tract infection in children. $\mathrm{N}$ Eng $\mathrm{J}$ Med. 2003;348(3):195-202.

19. Montini G, Rigon L, Zucchetta P, et al. Prophylaxis after first febrile urinary tract infection in children? Amulticenter, randomized, controlled, noninferiority trial. Pediatrics. 2008;122:1064-1071.

20. Lee MD, Lin CC, Huang FY, et al. Screening young children with a first febrile urinary tract infection for high-grade vesicoureteral reflux with renal ultrasound scanning and technetium-99mlabeled dimercaptosuccinic acid scanning. $J$ Pediatr. 2009;154:797-802.

21. Moorthy I, Easty A, McHugh K, et al. The presence of vesicoureteric reflux does not identify a population at risk for renal scarring following a first urinary tract infection. Arch Dis Child. 2005;90:733-736. 